УДК 613

\title{
СОСТАВ И ПРИМЕНЕНИЕ МИНЕРАЛЬНОЙ ВОДЫ НА КУРОРТАХ КАВКАЗСКИХ МИНЕРАЛЬНЫХ ВОД
}

\author{
Кузнецова Полина Игоревна \\ студент \\ Научный руководитель: Дрожжина Наталья Агафоновна \\ к.н., доцент кафедры общественного здоровья, \\ здравоохранения и гигиены \\ Российский университет дружбы народов (РУДН)
}

\begin{abstract}
Аннотация: Статья посвящена исследованию состава и применению минеральной воды в городах-курортах Кавказских Минеральных вод: город Кисловодск, город Ессентуки, а также ее применению и показаниям при наличии у отдыхающих определенных патологий организма.
\end{abstract}

Ключевые слова: Минеральная вода, питьевое лечение, состав минеральной воды, Кисловодск, Ессентуки.

\section{COMPOSITION AND APPLICATION OF MINERAL WATER IN THE RESORTS OF CAUCASIAN MINERAL WATERS}

\section{Kuznetsova Polina Igorevna Drozhzhina Natalia Agafonovna}

\begin{abstract}
The article is devoted to the study of the composition and application of mineral water in the resort-towns of Caucasian Mineral waters: Kislovodsk, Essentuki, as well as its using and indications in the presence of certain pathologies of vacationers.
\end{abstract}

Key words: Mineral water, drinking cure, composition of mineral water, Kislovodsk, Essentuki.

Кавказские Минеральные Воды - самый старый и крупный бальнеологический регион Российской Федерации, который зародился двести лет тому назад. Под понятием «бальнеологический курорт» понимают один из видов курорта, на котором в качестве основного фактора оздоровления 
используют природные минеральные воды. Кладом Кавказских Минеральных Вод и основным лечебным средством являются минеральные источники в количестве более трехсот [1].

Минеральные воды-подземные воды, включающие в себя высокое содержание биологически активных минеральных компонентов. Они обладают определенными физико-химическими свойствами: химический состав воды, температурный режим, радиоактивность, что в сумме оказывает лечебное действие на организм человека. Благодаря специфическому химическому составу и физическим свойствам минеральные воды используют как для наружного, так и для внутреннего применения в лечебных целях [2].

Минеральные воды формируются в толще земной коры, где происходит их естественная обработка, проходя сначала через горные, а затем-земные породы с разными условиями: геохимическими, геотермическими и гидрогеологическими, от которых и зависит температура воды, ее химические и физические свойства, микроэлементный состав [3]. При правильном употреблении минеральной воды происходит воздействие на организм температурой, гидростатическим давлением и ее химическим составом, происходит раздражение нервных рецепторов газами: сероводород, углекислый газ, оксид азота (IV), а также радиоактивными веществамирадоном, которые проникают к нам в организм через покровы кожи, слизистые оболочки, верхние дыхательные пути дыхательные пути, а затем в кровоток.

Состав минеральных вод обусловлен историей геологического развития территории, то есть характером тектонических структур, геотермическими условиями территории, откуда получают воду.

Употребляя свежую природную минеральную воду, в организме происходит замена клеточной воды, характеризующейся разрушенной структурой, на индивидуально структурированную воду. Данный процесс способствует увеличению времени жизни и эффективности работы всех клеток организма, благоприятно воздействуя на организм в целом, а это помогает организму в борьбе с внутренними очагами патологий. Минеральная вода содержит все соли необходимые для нормального функционирования нашего организма. Именно поэтому наилучшим путем восполнения недостатка солей в организме является употребление минеральной воды в определенной концентрации [4]. 
В соответствии с национальным стандартом Российской Федерации; Воды минеральные природные питьевые от 01.06.2012 минеральную воду, в зависимости от ее состава, классифицируют по разным группам:

1. По содержанию газов, специфических элементов минеральные воды классифицируют на:

- Углекислые

- Азотные

- Сероводородные, или сульфидные

- Кремниевые

- Мышьяковистые

- Железистые

- Йодистые

- Бромистые

- Радоновые, или радиоактивные

2. По температуре минеральные воды делят на:

- высокотермальные, или очень горячие $\left(\mathrm{t}=\right.$ от $42^{\circ} \mathrm{C}$ и выше)

- термальные, или горячие $\left(\mathrm{t}=37-42^{\circ} \mathrm{C}\right)$

- теплые $\left(\mathrm{t}=20-37^{\circ} \mathrm{C}\right)$

- холодные $\left(\mathrm{t}=\right.$ до $\left.20^{\circ} \mathrm{C}\right)$

3. По ионному составу минеральные воды принято делить на:

- Гидрокарбонатные

- Сульфатные

- Хлоридные

- Кальциевые

- Натриевые

- Магниевая

Гидрокарбонатно-сульфатные лечебно-столовые минеральные воды: небольшое содержание или полное отсутствие углекислого газа, органических веществ. Показания: гастриты с повышенной секреторной функцией; неосложненные язвенные болезни; хронические заболевания верхних дыхательных путей. Температурный режим: $\mathrm{t}=$ до $38-45^{\circ} \mathrm{C}$. Применение: в день больному необходимо пить минеральную воду 3 раза, желательно за час до приема пищи (или через час после приема пищи). Больному предлагают начать пить половину стакана, а концу курсу разрешается увеличить дозу до полтора стаканов [5]. 
Гидрокарбонатно-хлоридно-сульфатные лечебно-столовые воды. Показания: хронические заболевания печени, поджелудочной железы. Температурный режим: $\mathrm{t}=$ до $42-45^{\circ} \mathrm{C}$. Применение: в день больному необходимо пить минеральную воду 3 раза, желательно за час до приема пищи. Больному предлагают за один прием пить один или два стакана воды.

Гидрокарбонатно-сульфатные и минерально-органические лечебностоловые воды. Показания: хронические заболевания почек, мочевыводящих путей. Температурный режим: $\mathrm{t}=$ до $30-35^{\circ} \mathrm{C}$. Применение: в день больному необходимо пить минеральную воду 6-8 раз перед приемом пищи и через часдва часа после него. Больному предлагают за один прием пить 2-2,5 стакана воды [5].

Гидрокарбонатно-сульфатные кальциевые лечебно-столовые воды. Температурный режим: $\mathrm{t}=$ до $40-45^{\circ} \mathrm{C}$. Показания: хронические заболевания кишечника с повышенной моторикой. Применение: в день больному необходимо пить минеральную воду 3 раза в день за полчаса до еды. Больному предлагают за один прием пить половину стакана или один стакан. Противопоказания: если появляются боли в области живота, диарея необходимо временно прекратить питьевое лечение.

Хлоридно-сульфатные лечебные минеральные воды. Температурный режим: 18 - $24^{\circ} \mathrm{C}$. Показания: хронические заболевания со сниженной двигательной функцией кишечника, заболевания желчевыводящих путей, сахарный диабет, ожирение, подагра. Применение: в день больному необходимо пить один стакан минеральной воды 3 раза в сутки за полчаса до приема пищи и перед сном.

Гидрокарбонатно-йодные воды. Температурный режим: $\mathrm{t}=18-22^{\circ} \mathrm{C}$. Показания: заболевания щитовидной железы. Применение: в день больному необходимо пить минеральную воду 3 раза по одному стакану после приема пищи.

Железистые лечебно-столовые воды. Показание: железодефицитная анемия.

Минеральная вода благоприятно влияет на: повышение трофики клеток нашего организма; улучшение работы почек и функции мочевыводящих путей; печень и поджелудочную железу; моторику ЖКТ, на его всасывательную, секреторную функции, воздействуя минеральным, газовым составом минеральной воды; заживление язв, эрозий; гормональную деятельность ЖКТ, нормализуя ее [5]. 
Кисловодск- один из самых старых бальнеологических городов и является самым южным городом-курортом Кавказских Минеральных Вод, расположен в северных предгорьях на высоте около 1000 н.у.м. Здесь зародились минеральные воды 7-ми источников, богатые $\mathrm{Mg}$ и $\mathrm{Ca}$. Кисловодск знаменит «Нарзанами»-сульфатно-гидрокарбонатные натриевомагниево-кальциевые лечебно-столовые минеральные воды, являющиеся основой бальнеологического природного фактора. Они относятся к холодным минеральным источникам. Применяют «Нарзаны» как во внутрь, так и наружно. Наружное применение: нарзанные ванны, выписываемые терапевтом, благоприятно влияют на сердечно-сосудистую и нервную системы, назначают при болезнях кожи. Внутреннее применение: доломитный и сульфатный «Нарзан» применяют в качестве питьевого лечения при заболеваниях ЖКТ, мочевыводящих путей. Воды кисловодских источников используют для ингаляций, орошений, промываний [5].

Показания для применения минеральной воды «Нарзаны» внутрь и наружно:

1) Заболевания сердечно-сосудистой системы (нарзанные ванны): кардиопатия, ишемическая болезнь сердца, миокардиты, ревматизм, гипертоническая болезнь I-II стадий; остаточные явления на почве варикозного расширения вен, остаточные явления флебита.

2) Заболевания органов дыхания: бронхиальная астма, хронические неспецифические заболевания легких.

3) Заболевания нервной системы: цереброваскуляторные болезни; болезни периферической нервной системы: невриты, полиневрит, после удаления грыжи диска; болезни вегетативной нервной системы: соляриты, симпатоганглиониты (по окончании острого периода).

4) Сопутствующие заболевания органов пищеварения: хронический гастрит, колит, панкреатит, гепатит (в фазе ремиссии); энтероколит, язвенная болезнь двенадцатиперстной кишки (в фазе ремиссии).

5) Гинекологические заболевания: оофорит, эндометрит, параметрит, бесплодие (причина-воспалительные заболевания), хронический сальпингит.

6) Урологические заболевания: импотенция, хронический простатит.

7) Заболевания уха, горла, носа: тонзиллит, ринит, синусит, ларингит.

Все источники города Кисловодск родственны, так как имеют схожее содержание химических элементов, но в разных концентрациях, отличия друг от друга: степень насыщенности газами, общая минерализация. 
Минеральная вода известного источника «Нарзан», которая и явилась развитию курорту (гидрокарбонатно-сульфатная кальциево-магниевая). Общая минерализация: 1,8 г/л; Концентрация углекислоты: 1,0 г/л; Температура: $12^{\circ} \mathrm{C}$. Источник «Нарзан» до 1928 года был одним целебным источником города, и уже позже были обнаружены другие.

Воды доломитного нарзана. Общая минерализация: 5,0 г/л- показатель выше предыдущего, так как наблюдается повышение концентрации ионов $\mathrm{Na}$, $\mathrm{Cl}$; Концентрация углекислого газа: $>2,0$ г/л. Температура: $15-17^{\circ} \mathrm{C}$. Доломитный нарзан способствует улучшению обмен веществ организма, усилению мочеотделения, выведения из организма продуктов обмена.

Буровая 5/0-бис -занимает центр курорта Кисловодск. Общая минерализация: 1,9-2,0 г/л; Концентрация углекислоты: 1,2-1,4 г/л. Применяют для наружных процедур-ванны, орошение, ингаляции и пр.

Воды сульфатного нарзана. Общая минерализация: 5,2-6,7 г/л (высокий показатель из-за высокого содержания сульфатов $\mathrm{Mg}$, $\mathrm{Na}$; Концентрация углекислоты: 2 г/л; Микроэлементы, содержащиеся в воде: $\mathrm{B}, \mathrm{Sr}, \mathrm{Zn}, \mathrm{Mn}$; В воде сульфатного нарзана обнаруживается активное железо-15 мг/л, небольшая концентрация мышьяка. Особенность: высокое газосодержание. Применение: воды сульфатного нарзана улучшают секрецию желудка, моторику кишечника, желчевыводящую функцию печени.

Буровая №23-Желябовский нарзан (гидрокарбонатно-сульфатная кальциево-магниевая минеральная вода)-в настоящее время является одним из основных источников курорта, вода которого предназначена для приема внутрь. Буровая №23 была заложена позднее источника «Нарзан» на 21 год, но при этом является самой глубокой эксплуатационной скважиной города Кисловодск, глубина которой равна 308,2 м. Общая минерализация: 5,3 г/л; Концентрация углекислоты: 2,1 г/л. Вода Желябовского нарзана приятна на вкус и не обделена лечебными свойствами.

Углекислые воды, «Нарзаны» Кумского месторождения. Не расположены в Кисловодске, а поступают по нарзан-проводу (протяженность его 45 км) из посёлка Красный Восток (на востоке Кисловодска). Интересно заметить, что он является самым длинным в мире транспортером минеральной воды. Общая минерализация: 7,8 г/л (концентрация близка к Пятигорским горячим нарзанам, но отличается сравнительно низким уровнем сульфатов). Содержание углекислоты:1,5 г/л. Углекислые воды относят к холодным, железистым. Применяют в питьевых 
целях (неразведенный вид) и для бальнеолечения (при разведении водами источников: центрального Кисловодского и Березовского).

В водах кисловодских нарзанов содержат в небольших дозах биологически активные ионы, повышая ее лечебные свойства: $\mathrm{Cu}, \mathrm{Fe}, \mathrm{Mn}, \mathrm{Ag}$, $\mathrm{I}, \mathrm{Br}, \mathrm{Rn}$, ионы фосфорной, борной кислот.

На сегодняшний день в городе Кисловодск эксплуатируются десять источников «Нарзана», из которых в сутки допустимо отбирать около 1800 000 л воды (без вреда месторождению).

Город Ессентуки находится в долине реки Подкумок на высоте 600-650 м н.у.м. Издавна г. Ессентуки был и остается знаменит соляно-щелочными минеральными водами. Курорт насчитывает свыше 20 лечебных минеральных источников. В парках Ессентукского курорта размечены оздоровительные маршруты терренкура, расположены соляно-щелочные источники с минеральной водой «Ессентуки №4», «Ессентуки №17», «Новая» [7].

Ессентукские воды назначают больным, страдающим следующими заболеваниями:

1) Заболевания органов пищеварения: хронический гастрит, язвенная болезнь желудка, двенадцатиперстной кишки, панкреатиты, хронические колиты, гепатиты, энтероколиты, дискинезия желчных путей, желчного пузыря, желчнокаменная болезнь.

2) Заболевания органов дыхания: хронические бронхиты, пневмонии, трахеиты, трахеобронхиты с токсической, пылевой этиологией.

3) Эндокринные заболевания: полинейропатия, ангиопатия, сахарный диабет, алиментарное ожирение.

4) Урологические заболевания: мочекаменная болезнь, хронический простатит, цистит, пиелонефрит.

К Ессентукским минеральным источникам относятся минеральные углекислые гидрокарбонатно-хлоридные натриевые воды «Ессентуки № 4», «Ессентуки № 17», которые способствовали развитию лечебной базы в городе Ессентуки (главным образом с питьевым лечением) [6]. Целых 20 источников из всех минеральных источников данного курорта используются в качестве лечения приезжающих.

Минеральные воды «Ессентуки № 17»-лечебно-питьевые. Состав: хлоридно-гидрокарбонатный натриевый; Общая минерализация: 11,1-13,6 г/л (см. рис 1б. Приложение ); Температура: 1) холодные $\mathrm{t}=10^{\circ} \mathrm{C}$ (скважины: № 17-бис, 24, 24-бис, 36, 36-бис), 2) термальные $\mathrm{t}=36-37^{\circ} \mathrm{C}$ (скважины: 1-бис, № 
46). Концентрация углекислого газа: высокая насыщенность. Концентрация минеральных солей: высокая [4].

Действие минеральной воды «Ессентуки № 17» на организм:

- улучшает продукцию соляной кислоты желудком

- улучшает моторику ЖКТ

- повышает обменные процессы в организме

- оказывает благоприятное влияние на функцию печени, желчевыводящих путей, поджелудочной железы

- способствует улучшению общего состояния больных с хроническим гастритом, колитом [7].

Минеральные воды «Ессентуки № 4»- лечебные минеральные воды; лечебно-столовые в бутылках при розливе. Состав: хлоридногидрокарбонатный натриевый; Общая минерализация: 7,8-10,4 г/л (см. рис $1 \mathrm{a}$. Приложение); Концентрация углекислого газа (в растворенном виде): 0,52,0 г/л. Температура: 1) термальные (скважины: № 49-Э, 52), 2) холодные воды (относятся к Ессентукской группе источников) [6].

Действие минеральной воды «Ессентуки № 4» на организм схожи с действием «Ессентуки № 17»:

- повышает кислотообразующую функцию желудка

- двигательную функцию ЖКТ

- улучшает обменные процессы в организме при их нарушениях

- повышает функцию печени, поджелудочной железы, желчевыводящих, а также мочевыводящих путей

- положительно влияет на общее состояние больных, страдающими заболеваниями поджелудочной железы, желчевыводящих путей, хроническим гастритом, колитом

- помогает при расстройствах питания [7].

Углекислые сероводородные воды Ессентукского типа. Общая минерализация: 4,7-5,6 г/л; Концентрация углекислоты: $>1,0$ г/л; Концентрация сероводорода: 16 -20 мг/л, воды по этому показателю делят на: слабосульфидные (скважины: №1, №2) и сероводородные сульфатногидрокарбонатные кальциево-натриевые воды (Гаазо-Пономаревский источник).

Углекислые воды сложного ионного состава. 1) Хлоридно-гидрокарбонатные натриево-кальциевые воды. Общая минерализация: 7,7 г/л; 
Температура: $\mathrm{t}=+42^{\circ} \mathrm{C}$ (термальные); Содержание элементов: повышенное содержание магния, сульфатов. 2) Слабоминерализованные хлоридносульфатно-гидрокарбонатные натриевые воды. Общая минерализация: 0,7 г/л; Температура: $\mathrm{t}=+43^{\circ} \mathrm{C}$ (термальные); Применение: питьевое лечение, бальнеопроцедуры.

Минеральная вода Ессентуки «Новая». Содержит кремний (H2SiO3) в концентрации 50-80 мг/л, что определяет еe мочегонной эффект гидрокарбонатов. «Новую» рекомендуют больным с заболеваниями почек, мочевыводящих путей, органов пищеварения; с нарушением у больного трофики тканей, обмена веществ. Минеральную воду Ессентуки «Новая» в народе прозвали «эликсиром молодости и красоты», так как были замечены ее способности восстанавливать эластичность тургора кожи, гладкость и влажность кожных покровов.

Так, в каждом курортном городе минеральная вода имеет свой состав и обладает индивидуальными лечебными свойствами.

\section{Список литературы}

1. Павлова А.В., Крылова О.В., Васнецова О.А. Минеральные воды России: история и современность (правовые аспекты потребления)// Ремедиум. 2017. №11. С. 27-29.

2. Распоряжение Правительства Ставропольского края от 13.06.2019 №219-рп об утверждении Концепции сохранения, восстановления и развития особо охраняемого эколого-курортного региона Российской ФедерацииКавказские Минеральные Воды в границах территории Ставропольского края. [Электронный ресурс] // URL: https://docs.cntd.ru/document/553370675 (Дата обращения: 17.11.2021)

3. Потапов Е.Г., Ляшенко С.И. Особенности формирования радиологического состава минеральных вод региона $\mathrm{KMB} / /$ Геологическая эволюция взаимодействия воды с горными породами. 2020. С.103-106.

4. Репс В.Ф., Котова М.Е., Беловодова С.Е. Биологические эффекты и основные направления модификации минеральных вод региона Кавказские Минеральные Воды//Современная наука и инновации. 2017. №4(20). С. 205209. 
5. Лечение минеральной водой на курортах Кавказских Минеральных Вод. -г. Минеральные Воды: АО «Издательство «Кавказская здравница»// под ред. Синкевич Е. - 2018. С. 1-72

6. Гончар Ю.Н., Гудыменко В.А., Гудыменко Н.О. Химические и радиологические исследования минеральных вод «Ессентуки №4» и «Ессентуки №17»// АНРИ. 2011. №1 (64). С.65-70.

7. Фальков Г.А. Лечение минеральной водой. Самые популярные курорты//Международная научно-техническая конференция молодых ученых БГТУ им. В.Г.Шухова. 2018. С.1352-1357. 